\title{
A Simple Foot Plantar Pressure Measurement Platform System Using Force-Sensing Resistors
}

\author{
Dwi Basuki Wibowo ${ }^{1}$, Agus Suprihanto ${ }^{1}$, Wahyu Caesarendra ${ }^{2, *} \mathbb{D}$, Slamet Khoeron ${ }^{1}$, \\ Adam Glowacz ${ }^{3}$ (D) and Muhammad Irfan ${ }^{4}$ (D) \\ 1 Mechanical Engineering Department, Diponegoro University, Jl. Prof. Soedharto, SH, Tembalang, \\ Semarang 50275, Indonesia; rmt.bowo@gmail.com (D.B.W.); agusm90@yahoo.com (A.S.); \\ Slametkhoeron@students.undip.co.id (S.K.) \\ 2 Faculty of Integrated Technologies, University Brunei Darussalam, Jalan Tungku Link, \\ Gadong BE1410, Brunei Darussalam \\ 3 Department of Automatic Control and Robotics, Computer Science and Biomedical Engineering, Faculty of \\ Electrical Engineering, Automatics, AGH University of Science and Technology, al. A. Mickiewicza 30, \\ 30-059 Kraków, Poland; adglow@agh.edu.pl \\ 4 Electrical Engineering Department, College of Engineering, Najran University Saudi Arabia, \\ Najran 61441, Saudi Arabia; miditta@nu.edu.sa \\ * Correspondence: wahyu.caesarendra@ubd.edu.bn
}

Received: 16 June 2020; Accepted: 28 July 2020; Published: 4 August 2020

check for updates

\begin{abstract}
Generally, there are two types of working style, i.e., some people work in sitting conditions, and the remaining work mostly in a standing position. For people working in a standing position, they can spend hours in a day doing their work standing. These people do not realize that it can cause medical issues, especially for the feet, namely biometric problems. In addition, several doctors in Indonesia are already aware of this issue and state that the biometric problems faced by those kinds of people can be predicted from the load distribution on the foot. However, the tool used by the doctors in Indonesia to measure biometric problems is not a digital tool. Therefore it is very difficult to measure and predict the biometric problems quantitatively. This study aims to develop a low-cost static load measuring device using force-sensing resistor (FSR) sensors. The measuring instrument is designed in the form of a pressure plate platform which consist of 30 FSR 402 sensors. The sensors are placed right underneath the display area of the foot, 15 sensors on the soles of the left and right feet. Ten students from the Department of Mechanical Engineering, Diponegoro University (five men and five women) were asked to stand on the platform. Each subject also measured foot length (FL) to estimate shoe size, foot area contact (FAC) for validation between genders, and foot type using the digital footprint tools. From the results of measurements obtained for the left foot in the medial mid foot area, i.e., in sensors 5 and 7, not exposed to the load, on almost all subjects except subject number 3 with a load of $0.196 \mathrm{~kg}$ on sensor 7 . The highest average load occurs in the heel area i.e., sensor 1 measured $0.713 \mathrm{~kg}$ and the smallest average load occurs in the five sensors, with $0 \mathrm{~kg}$. A static load gauge that is designed to be used to measure each leg area for subjects with a shoe size of 40-42 with low price to be held in hospital-orthopedic hospitals and biomechanical research centers.
\end{abstract}

Keywords: biometric; FSR sensors; biomechanical; static load gauge

\section{Introduction}

Many people spend part of their time standing, but not many doctors in Indonesia know the biometric problems faced by them can be predicted from the load distribution on the foot. The amount of load on the foot depends on body weight (BW) and gender. The results of the previous study showed that while standing bare foot, the heel and arch areas bore a burden of about $70 \%$ BW, while the 
metatarsal area and toe toes bore 30\% BW [1]. The results of the study also proved the burden on the soles of women's feet is larger than men [2].

Load distribution in the foot can also show the stability of the body when standing, which is from counting trips of the Center of Pressure (COP) speed swaying at mediolateral and anteroposterior directions measured using force plate [3]. When people walk, the stability and risk of fall can be identified from the COP trajectory. The identification is obvious for example, when COP trajectory in the arch area of one leg is on the lateral side of the arch (high arch) while the other leg is normal. In addition, the measurement of the load on the sole of the foot when standing can also show the comparison of load between legs which can be known from the calculation of the asymmetry index (ASI). The type of foot (high arch, normal, or flat foot) can also be predicted from the load ratio in the arch area to the load across the soles of the foot without the radius [4], the most accurate way to know the type of foot is to scan the foot (footprint scanning) using Cavanagh's method [5].

Measurement of load distribution on the foot was also used in several countries to evaluate the development of the treatment of diabetics, there are injuries in the foot ulcer, nerve death (neuropathy), or before and post-foot amputation [6]. Interpretation of the load distribution data of diabetics is not easy, requires the history of the disease and the treatment that has been done as well as changes in the measurement result of load distribution at any time. In comparison with people with arthritis and joints pain (osteoarthritis), interpretation of its burden distribution data is easier, because it is obvious from the difference of load distribution between the soles of the left and right feet and static posture that is not upright because they feel pain compared with healthy people (normal foot) [7].

The results of the load distribution measurements on the foot are also used as a base for designing orthotic shoe soles for pain sufferers in the heel area due to the inferior calcaneus spur, where the burden in the area should be equal to or smaller than the minimum pain pressure gained from the measurement using Algometer [8].

The foot gauge pressure measuring platform is a tool for measuring the load of static contacts between foot and base. This measuring instrument is an electronic device with a piezoelectric transducer which will produce voltage change [9] or force the sensing resistor (FSR) sensor [10] which will produce resistance change when receiving pressure. This paper aims to develop a low-cost static load measuring device using FSR sensors. This is because similar products with thousands of FSR sensors are expensive, up to US $\$ 20,000$ [11], so it is a burden for hospitals and biomechanical research centers in Indonesia to use this kind of measurement.

\section{Materials and Methods}

Measuring instrument is designed to consist of 30 FSR 402 sensors. Sensors are made by Interlink Electronics with a diameter of $12.7 \mathrm{~mm}$, a thickness of $0.46 \mathrm{~mm}$, a range of style sensitivity of $100 \mathrm{~g}-10 \mathrm{~kg}$, and a range of pressure sensitivity of 1.5-150 psi [12]. Prior to the experiment, each sensor was calibrated by applying an initial testing load (0-6000 $\mathrm{g}$ with increasing interval of $200 \mathrm{~g}$ ) in the active area of the sensor. The determination of the calibration load limit of $6000 \mathrm{~g}$ is based on the results of previous studies using the same sensor which shows the load in the largest heel area for flat insole is only $3.35 \mathrm{~kg} / \mathrm{cm}^{2}$ (43 g with $12.7 \mathrm{~mm}$ active area diameter) [8]. The characteristics of the sensor behavior response is presented in Figure 1 [13]. From the validation results obtained, the relationship $\mathrm{V}$ (Volt) and L (kg) in the form of polynomial Equation (1) is as follows:

The red solid line in Figure 1 indicates the polynomial fit of the calibration measurement graph between voltage (volt) and load ( $\mathrm{kg}$ ). The polynomial fit equation is expressed below:

$$
\mathrm{L}=927.7757 \mathrm{~V}^{3}-1643.867 \mathrm{~V}^{2}+1083.49 \mathrm{~V}-31.02378
$$




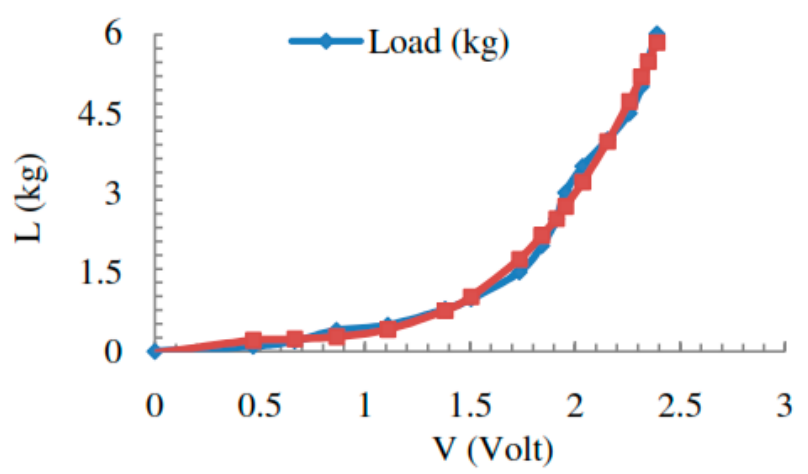

Figure 1. Relationship between voltage (V) and load (kg) of FSR 402 sensor.

The dimensions of the $40 \times 40 \times 6 \mathrm{~cm}$ tool are made of a $3 \mathrm{~mm}$ thick steel plate frame and platform is made of $10 \mathrm{~mm}$ thick multiplex. On the measuring platform there is a display of foot to guide the subject while standing on it, as presented in Figure 2a. The sensors are attached right underneath the display area of the foot, 15 sensors on the soles of the left and right foot. To obtain a fully covered load distribution on the foot, the measurement are divided into four areas i.e., heel area or rear foot (heel or rear $31 \%$ of foot length (FL)), middle (arch or mid foot, 58\% FL), front without the radius of the foot $(85 \% \mathrm{FL})$, and the radius of the foot (100\% FL) [14].

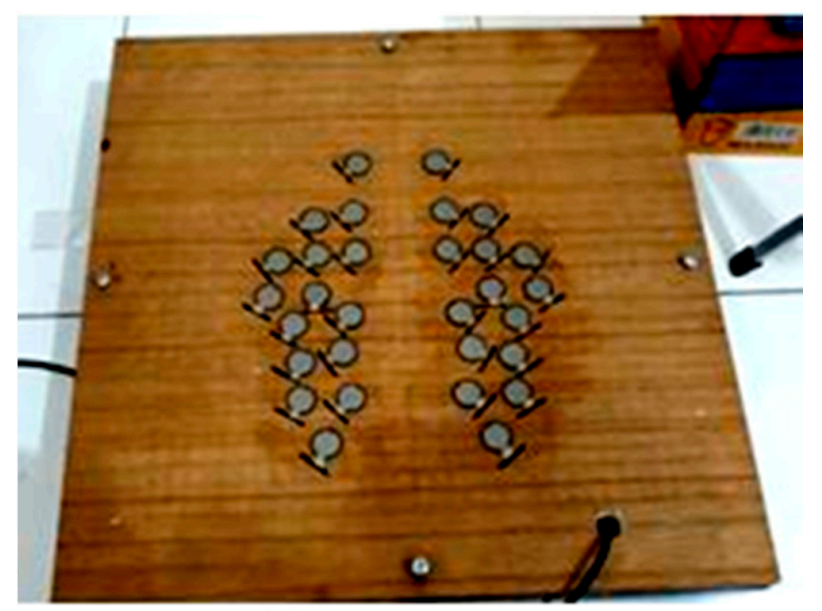

(a)

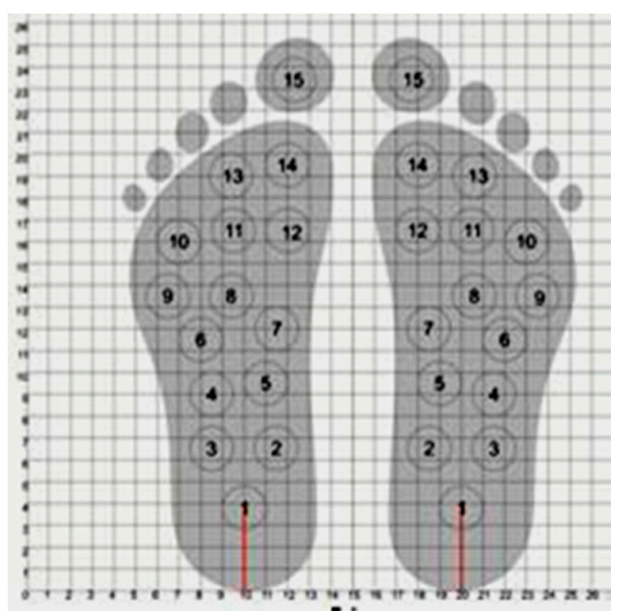

(b)

Figure 2. Simple foot static load measuring device: (a) measurement platform, (b) the location of the sensor placement.

Sensor placement position is presented in Figure 2b.Three sensors are attached on the rear foot (sensor \#1-\#3) where the sensor 1 is placed in the center of heel $(\mathrm{CH})$ [15].Other four sensors are attached on mid foot (sensor \#4-\#7) and the remaining seven sensors are placed in the front area without the radius of the foot (sensor \#8-\#14), and one sensor is located on the thumb toe (sensor \#15). The designed tool is used to scan the weight of the subject soles with a shoe size of 42 ( $F L=25.9 \mathrm{~cm}$ ). However, the coordinate placement of the sensors, as seen in Table 1, is still valid in the subjects with the shoe sizes 40 and 41.

Figure 3 shows the hardware and software of the built-in foot static load gauge system. Each FSR sensor is connected to one $2.7 \mathrm{k} \Omega$ resistor. The sensor output voltage is read by the Arduino MEGA 2560 microcontroller using a 15 pin analog input bit [16]. Then, the voltage is sent to the DAQ LabVIEW software via a USB serial to be converted into loads using Equation (1). To process and display data on a computer screen according to the wishes of the software interface with C\# or C Sharp language. The use of C\# language allows intertwined communication with software in LabVIEW. 
Table 1. The coordinate placement of the sensors.

\begin{tabular}{ccccccccccccccccc}
\hline \multicolumn{11}{c}{ On the Left and Right Leg Soles $(\mathbf{c m})$} \\
\hline & $\mathbf{1}$ & $\mathbf{2}$ & $\mathbf{3}$ & $\mathbf{4}$ & $\mathbf{5}$ & $\mathbf{6}$ & $\mathbf{7}$ & $\mathbf{8}$ & $\mathbf{9}$ & $\mathbf{1 0}$ & $\mathbf{1 1}$ & $\mathbf{1 2}$ & $\mathbf{1 3}$ & $\mathbf{1 4}$ & $\mathbf{1 5}$ \\
\hline $\mathrm{x} 1$ & 0.0 & 1.5 & -1.5 & -1.5 & 1.0 & -2.0 & 1.5 & -0.6 & -3.5 & -3.0 & -0.5 & 2.0 & -0.6 & 2.0 & 2.3 \\
$\mathrm{x} 2$ & 0.0 & -1.5 & 1.5 & 1.5 & 1.0 & 2.0 & -1.5 & 0.6 & 3.5 & 3.0 & 0.5 & -2.0 & 0.6 & -2.0 & -2.3 \\
$\mathrm{y}$ & 3.8 & 6.5 & 6.5 & 9.0 & 9.5 & 11.5 & 12.0 & 13.5 & 13.5 & 16.0 & 16.5 & 16.5 & 19.0 & 19.5 & 23.4 \\
\hline
\end{tabular}

Description: $\mathrm{x} 1$ and $\mathrm{x} 2$ are local coordinates $\mathrm{x}$ left and right foot soles.

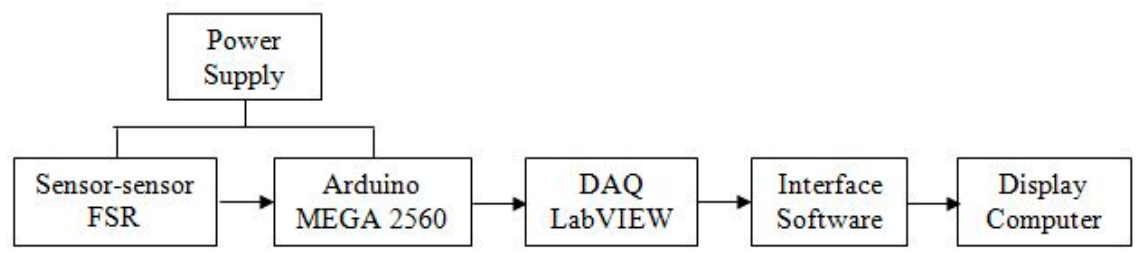

Figure 3. Block diagram system of static load gauge of soles.

\section{Results and Discussion}

In the early stages of this measuring instrument prototype, 10 students from the Department of Mechanical Engineering, Diponegoro University participated in the study. Details on the subjects in the study are presented in Table 2. The weight and height were measured with body mass index (BMI) digital tools [17]. While FL, the contact area of the foot (FAC: Foot contact) and foot type (high arch, normal, flat foot) were measured by digital footprint tools [18].

Table 2. A detail information of participated subjects in this study.

\begin{tabular}{|c|c|c|c|c|c|c|c|c|}
\hline $\begin{array}{c}\text { No. } \\
\text { Subject }\end{array}$ & $\begin{array}{l}\text { Gender } \\
(\mathrm{M} / \mathrm{F})\end{array}$ & $\begin{array}{c}\text { Weight } \\
\text { Agency (kg) }\end{array}$ & $\begin{array}{c}\text { High } \\
\text { Agency (cm) }\end{array}$ & $\begin{array}{c}\text { BMI } \\
\left(\mathrm{kg} / \mathrm{m}^{2}\right)\end{array}$ & $\begin{array}{c}\text { FL } \\
(\mathrm{mm})\end{array}$ & $\begin{array}{l}\text { Shoe } \\
\text { Size }\end{array}$ & $\begin{array}{c}\text { FAC } \\
\left(\mathrm{mm}^{2}\right)\end{array}$ & $\begin{array}{l}\text { Foot } \\
\text { Type }\end{array}$ \\
\hline 1 & $\mathrm{M}$ & 52.8 & 171 & 18.1 & 250.0 & 40 & 8505.6 & $\mathrm{HA}$ \\
\hline 2 & $\mathrm{~F}$ & 64.8 & 175 & 21.2 & 258.0 & 42 & $12,392.0$ & NA \\
\hline 3 & M & 68 & 166 & 24.7 & 257.0 & 42 & $14,204.3$ & LA \\
\hline 4 & M & 71.5 & 171 & 24.3 & 249.1 & 40 & $14,332.1$ & NA \\
\hline 5 & M & 84.7 & 173 & 28.4 & 255.8 & 41 & $14,954.0$ & LA \\
\hline 6 & M & 75.2 & 168 & 26.6 & 255.5 & 41 & $12,038.1$ & NA \\
\hline 7 & $\mathrm{~F}$ & 71.6 & 168 & 25.5 & 252.0 & 41 & $11,451.4$ & HA \\
\hline 8 & F & 54.4 & 170 & 18.8 & 254.5 & 41 & $12,221.8$ & HA \\
\hline 9 & $\mathrm{~F}$ & 54.7 & 167 & 19.7 & 249.2 & 40 & 9456.1 & $\mathrm{HA}$ \\
\hline 10 & F & 55.8 & 174 & 18.4 & 255.7 & 41 & $11,029.1$ & HA \\
\hline
\end{tabular}

Note: high arch (HA); normal arch (NA); low arch (LA) (flat foot).

From the FL data, sensors in each area of the measuring instrument (rear foot area, mid foot, without the toes of the foot, and thumb fingers) are still in the same area on the foot of the entire subject, as presented in Table 2. This indicates that each foot area of all subjects with shoe size of $40-42$ has similar measurement within the sensors on the rear foot area (sensor 1-3), mid foot area (sensor 4-7), front foot area (sensors 8-14), and thumb finger area (sensor 15).According to the FAC data, it is shows that the average FAC for males are larger than females, which are $12,806.8 \mathrm{~mm}^{2}$ and $11,310.1 \mathrm{~mm}^{2}$, respectively $[2,19]$. There are five subjects with a high arch foot type, three normal arch subjects, and two low arch subjects. It is called high arch when $\mathrm{AI} \leq 0.21$, normal arch when $0.26 \geq \mathrm{AI}>0.21$, and low arch when $\mathrm{AI}>0.26$, where $\mathrm{AI}$ is the Arch Index as defined by Cavanagh [5].

The data of the load measurement results in each sensor is presented in Tables 3 and 4 for the soles of the left and right foot, respectively. The measuring result proves the burden on the soles of women's feet is greater than that of men [2]. It is seen from the magnitude of the total sensor load ratio 
against $0.5 \mathrm{BW}(\%)$, i.e., for the left leg: $16.8 \%$ male and $19.3 \%$ female and right foot: $22.7 \%$ male and $23.2 \%$ female. It is also indicated in the measurement that majority of the subjects were right-footed. This is also the evident from the previous study that described the total load difference of the average sensor at the right-footed greater than $21.9 \%$ compared to the left foot [19].

Table 3. Load data on the soles of left leg 10 research subjects.

\begin{tabular}{|c|c|c|c|c|c|c|c|c|c|c|c|c|c|c|c|c|}
\hline \multirow{2}{*}{$\begin{array}{c}\text { No. } \\
\text { Subject }\end{array}$} & \multicolumn{15}{|c|}{ Load Per Sensor (Gram) } & \multirow{2}{*}{$\begin{array}{l}\text { Total Load } \\
\text { Sensor (kg) }\end{array}$} \\
\hline & 1 & 2 & 3 & 4 & 5 & 6 & 7 & 8 & 9 & 10 & 11 & 12 & 13 & 14 & 15 & \\
\hline 1 & 702 & 210 & 290 & 0 & 0 & 0 & 0 & 0 & 0 & 0 & 350 & 302 & 540 & 342 & 787 & 3.5 \\
\hline 2 & 644 & 517 & 437 & 527 & 0 & 363 & 0 & 169 & 0 & 426 & 526 & 429 & 514 & 398 & 516 & 5.5 \\
\hline 3 & 727 & 583 & 657 & 623 & 0 & 654 & 196 & 454 & 0 & 474 & 643 & 627 & 688 & 592 & 766 & 7.7 \\
\hline 4 & 731 & 617 & 710 & 686 & 0 & 690 & 0 & 318 & 0 & 457 & 522 & 449 & 673 & 601 & 257 & 6.7 \\
\hline 5 & 694 & 441 & 662 & 547 & 0 & 557 & 0 & 249 & 0 & 612 & 489 & 278 & 665 & 558 & 424 & 6.2 \\
\hline 6 & 736 & 700 & 641 & 476 & 0 & 373 & 0 & 0 & 0 & 470 & 438 & 263 & 634 & 471 & 354 & 5.6 \\
\hline 7 & 706 & 571 & 606 & 550 & 0 & 428 & 0 & 0 & 2 & 283 & 453 & 474 & 723 & 705 & 705 & 6.2 \\
\hline 8 & 776 & 561 & 467 & 355 & 0 & 334 & 0 & 11 & 0 & 467 & 689 & 545 & 699 & 542 & 756 & 6.2 \\
\hline 9 & 764 & 574 & 493 & 435 & 0 & 392 & 0 & 0 & 370 & 332 & 325 & 0 & 784 & 656 & 686 & 5.8 \\
\hline 10 & 654 & 455 & 542 & 540 & 0 & 576 & 0 & 0 & 418 & 270 & 0 & 0 & 578 & 392 & 681 & 5.1 \\
\hline
\end{tabular}

Table 4. Load data on the soles of right leg 10 research subjects.

\begin{tabular}{|c|c|c|c|c|c|c|c|c|c|c|c|c|c|c|c|c|}
\hline \multirow{2}{*}{$\begin{array}{c}\text { No. } \\
\text { Subject }\end{array}$} & \multicolumn{15}{|c|}{ Load Per Sensor (Gram) } & \multirow{2}{*}{$\begin{array}{l}\text { Total Load } \\
\text { Sensor }(\mathrm{kg})\end{array}$} \\
\hline & 1 & 2 & 3 & 4 & 5 & 6 & 7 & 8 & 9 & 10 & 11 & 12 & 13 & 14 & 15 & \\
\hline 1 & 810 & 567 & 549 & 0 & 0 & 0 & 0 & 0 & 525 & 714 & 625 & 300 & 737 & 571 & 784 & 6.2 \\
\hline 2 & 715 & 51 & 692 & 621 & 0 & 535 & 0 & 229 & 676 & 792 & 718 & 681 & 678 & 446 & 631 & 7.5 \\
\hline 3 & 699 & 739 & 664 & 680 & 479 & 635 & 394 & 625 & 635 & 634 & 572 & 517 & 654 & 623 & 824 & 9.4 \\
\hline 4 & 785 & 725 & 665 & 614 & 118 & 578 & 0 & 434 & 562 & 574 & 531 & 573 & 666 & 580 & 571 & 8.0 \\
\hline 5 & 823 & 670 & 740 & 684 & 420 & 626 & 487 & 469 & 612 & 669 & 482 & 511 & 685 & 730 & 641 & 9.2 \\
\hline 6 & 745 & 649 & 770 & 461 & 381 & 401 & 1 & 513 & 364 & 581 & 694 & 691 & 685 & 551 & 411 & 7.9 \\
\hline 7 & 819 & 780 & 693 & 632 & 74 & 549 & 0 & 0 & 482 & 617 & 350 & 466 & 762 & 738 & 722 & 7.7 \\
\hline 8 & 860 & 480 & 639 & 0 & 0 & 0 & 0 & 0 & 91 & 529 & 550 & 678 & 565 & 530 & 820 & 5.7 \\
\hline 9 & 721 & 405 & 413 & 387 & 0 & 533 & 0 & 217 & 425 & 721 & 608 & 533 & 788 & 685 & 554 & 7.0 \\
\hline 10 & 691 & 690 & 429 & 550 & 0 & 418 & 0 & 0 & 0 & 509 & 300 & 900 & 763 & 533 & 464 & 6.2 \\
\hline
\end{tabular}

Figure 4 presents the measurement of static load and the display of the results on a computer screen. The colors on the sensors (yellow and green) presented in Figure $4 \mathrm{~b}$ indicate that the sensors are exposed to the external load from the subject being measured. In addition, the green spots indicate that the measurement points have higher load than the yellow spots.

According to the measurement results, it is noted that the left foot in medial mid foot area, i.e., in sensors 5 and 7 are not exposed to the load. This result was revealed in almost all subjects except subject number 3, with a load of $0.196 \mathrm{~kg}$ on sensor 7 . The highest average load occurs in the heel area i.e., at a sensor 1 the average is $0.713 \mathrm{~kg}$ and the smallest average load occurs in the sensor 5 , $0 \mathrm{~kg}$. In the soles of the right leg the smallest average load occurs in the medial mid foot area as well, i.e., each amounting to $0.147 \mathrm{~kg}$ in sensor 5 and $0.088 \mathrm{~kg}$ in sensor 7 . Meanwhile, the largest average load occurs in the heel area indicated on sensor 1 of $0.767 \mathrm{~kg}$. The measuring result also shows the burden in the heel area and the arch is larger than in the metatarsal area and the thumb is $86.9 \%$ and $70.5 \%$ respectively for the left and right foot [1]. In addition, when the load stands quite large occurs in the first and second metatarsal area (sensors 13 and 14) and thumb (sensor 15) [8] namely $0.650 \mathrm{~kg}$, $0.526 \mathrm{~kg}$, and $0.593 \mathrm{~kg}$ for the left leg and $0.698 \mathrm{~kg}, 0.599 \mathrm{~kg}$, and $0.642 \mathrm{~kg}$ for the right leg. 


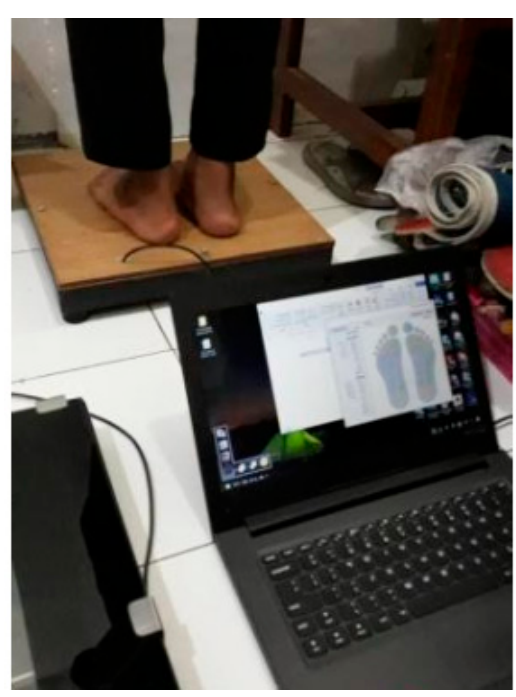

(a)
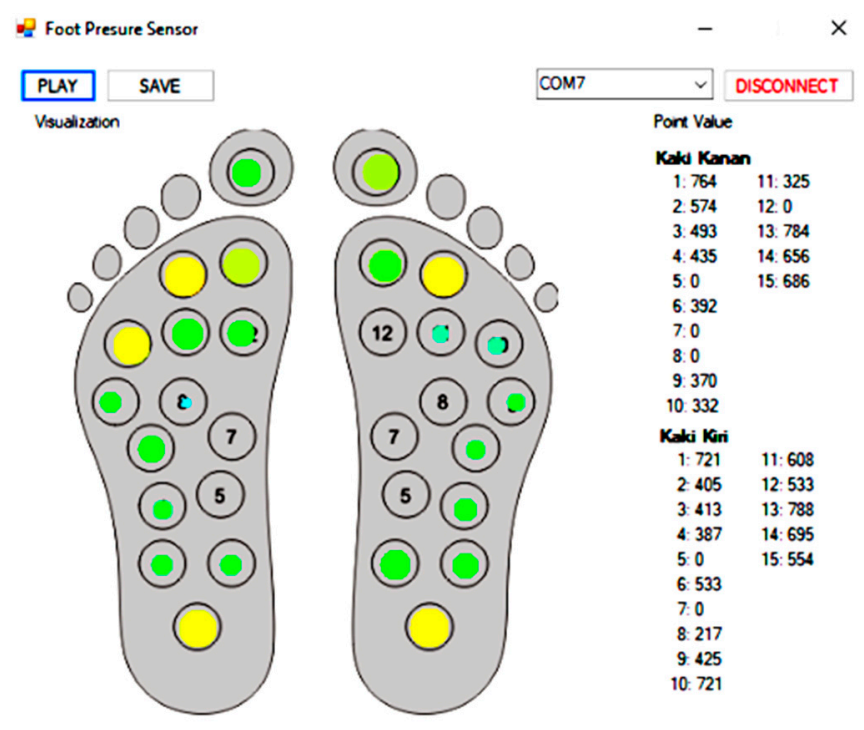

(b)

Figure 4. Method of measurements static load of foot (a) and display result (b). Note: Kaki Kanan (Right Foot) and Kaki Kiri (Left Foot).

The asymmetry of the foot between the left and right leg can be known from by calculating the asymmetry index (ASI) using the following formula [20]:

$$
\mathrm{ASI}=((\mathrm{DL}-\mathrm{NDL}) / \mathrm{DL}) \times 100
$$

where DL and NDL are dominant and non-dominant leg respectively and the right leg used as the basis calculation. The term DL is only to describe the load on the sole of one foot is greater than the other. From the calculation of ASI (\%), as shown in Table 5, almost all subjects showed that standing on the right foot was more dominant than the left foot, seen from the positive ASI value in all areas of the sole of the foot. Significant differences in negative ASI values were seen in the thumb finger area of subjects' numbers 9 and 10. This could be due to the two subjects not really standing straight when measured. The fact that almost all subjects were more dominant with their right foot than with their left foot when standing can be seen from the total load of all sensors (last column in Table 5). There is 
no previous research that proves when standing the right foot is more dominant than the left foot except when they jump high during playing volleyball and basketball [20].

Table 5. The calculation of ASI (\%) of each area of every subject.

\begin{tabular}{|c|c|c|c|c|c|c|c|c|c|c|c|c|c|c|}
\hline \multirow{3}{*}{ Subject \# } & \multicolumn{12}{|c|}{ Total Load Sensors in Area (Gram) } & \multicolumn{2}{|c|}{$\begin{array}{l}\text { Total Load All } \\
\text { Sensors (kg) }\end{array}$} \\
\hline & \multicolumn{3}{|c|}{ Rear Foot } & \multicolumn{3}{|c|}{ Mid Foot } & \multicolumn{3}{|c|}{ Front Foot } & \multicolumn{3}{|c|}{ Thumb Finger } & \multirow[b]{2}{*}{$\begin{array}{l}\text { Left } \\
\text { Leg }\end{array}$} & \multirow[b]{2}{*}{$\begin{array}{c}\text { Right } \\
\text { Leg }\end{array}$} \\
\hline & $\begin{array}{l}\text { Left } \\
\text { Leg }\end{array}$ & $\begin{array}{l}\text { Right } \\
\text { Leg }\end{array}$ & $\begin{array}{l}\text { ASI } \\
(\%)\end{array}$ & $\begin{array}{l}\text { Left } \\
\text { Leg }\end{array}$ & $\begin{array}{l}\text { Right } \\
\text { Leg }\end{array}$ & $\begin{array}{l}\text { ASI } \\
(\%)\end{array}$ & $\begin{array}{l}\text { Left } \\
\text { Leg }\end{array}$ & $\begin{array}{l}\text { Right } \\
\text { Leg }\end{array}$ & $\begin{array}{l}\text { ASI } \\
(\%)\end{array}$ & $\begin{array}{l}\text { Left } \\
\text { Leg }\end{array}$ & $\begin{array}{l}\text { Right } \\
\text { Leg }\end{array}$ & $\begin{array}{l}\text { ASI } \\
(\%)\end{array}$ & & \\
\hline 1 & 1202 & 1926 & 37.6 & 0 & 0 & 0 & 1535 & 3472 & 55.79 & 787 & 784 & -0.4 & 3.5 & 6.2 \\
\hline 2 & 1598 & 1458 & -9.6 & 890 & 1156 & 23.0 & 2464 & 4220 & 41.61 & 516 & 631 & 18.2 & 5.5 & 7.5 \\
\hline 3 & 1967 & 2102 & 6.4 & 1473 & 2188 & 32.7 & 3481 & 4260 & 18.29 & 766 & 824 & 7.0 & 7.7 & 9.4 \\
\hline 4 & 2058 & 2175 & 5.4 & 1376 & 1310 & -5.0 & 3024 & 3920 & 22.86 & 257 & 571 & 55.0 & 6.7 & 8 \\
\hline 5 & 1797 & 2233 & 19.5 & 1104 & 2217 & 50.2 & 2856 & 4158 & 31.31 & 424 & 641 & 33.9 & 6.2 & 9.2 \\
\hline 6 & 2077 & 2164 & 4.0 & 849 & 1244 & 31.8 & 2282 & 4079 & 44.05 & 354 & 411 & 13.9 & 5.6 & 7.9 \\
\hline 7 & 1883 & 2292 & 17.8 & 978 & 1255 & 22.1 & 2647 & 3415 & 22.49 & 705 & 722 & 2.4 & 6.2 & 7.7 \\
\hline 8 & 1804 & 1979 & 8.8 & 689 & 0 & 0 & 2961 & 2943 & -0.61 & 756 & 820 & 7.8 & 6.2 & 5.7 \\
\hline 9 & 1831 & 1539 & -19.0 & 827 & 920 & 10.1 & 2476 & 3977 & 37.74 & 686 & 554 & -23.8 & 5.8 & 7 \\
\hline 10 & 1651 & 1810 & 8.8 & 1116 & 968 & -15.3 & 1668 & 3005 & 44.49 & 681 & 464 & -46.8 & 5.1 & 6.2 \\
\hline
\end{tabular}

The measurement results obtained from the proposed low-cost measurement instrument used in this study are compared with Multi Array Foot Pressure (MAFP) measurement research result [21] that consisting of 625 FSR 400 sensors, as shown in Figure 5. The red color indicates the greatest load of foot while the least load represents by the dark blue color. The purpose of this comparison is not on validity of the value of load on the soles of each subject, but rather on the validity of the area of the affected foot and weight distribution pattern that occurs for each type of foot soles as shown in Table 6 .


Figure 5. MAFP tool research results that also used in previous study by Wibowo et al. [21]. 
Table 6. Sample comparison of measuring instrument results designed with MAFP measurement (sorted against type soles of foot).

\begin{tabular}{|c|c|c|c|c|}
\hline Type Soles of Foot & $\begin{array}{c}\text { Display of Designed Measuring Instruments } \\
\text { and MAFPM }\end{array}$ & \multicolumn{3}{|c|}{ Total Load in Each Area of Foot } \\
\hline \multirow{12}{*}{ High Arch } & & \multicolumn{3}{|c|}{$\begin{array}{l}\text { Subject No.: } 1 \\
\text { Total load of the foot (gram) }\end{array}$} \\
\hline & & Area & Left & Right \\
\hline & & Rear & 1202 & 1926 \\
\hline & & Middle & 0 & 0 \\
\hline & & Front & 1534 & 3472 \\
\hline & & & & \\
\hline & & Subject No & & \\
\hline & & Area & Left & Right \\
\hline & & Rear & 1804 & 1979 \\
\hline & & Middle & 689 & 0 \\
\hline & & Front & 2953 & 2943 \\
\hline & & Thumb & 756 & 820 \\
\hline \multirow{12}{*}{ Normal Arch } & & $\begin{array}{l}\text { Subject No } \\
\text { Total load }\end{array}$ & t (gram) & \\
\hline & & Area & Left & Right \\
\hline & & Rear & 1598 & 1458 \\
\hline & & Middle & 890 & 1156 \\
\hline & & Front & 2462 & 4220 \\
\hline & & Thumb & 516 & 631 \\
\hline & & Subject No & 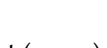 & \\
\hline & & Area & Left & Right \\
\hline & & Rear & 2077 & 2164 \\
\hline & & Middle & 849 & 1243 \\
\hline & & Front & 2276 & 4079 \\
\hline & & Thumb & 354 & 411 \\
\hline \multirow{13}{*}{ Low Arch } & & \multicolumn{3}{|c|}{$\begin{array}{l}\text { Subject No.: } 3 \\
\text { Total load of the foot (gram) }\end{array}$} \\
\hline & & Area & Left & Right \\
\hline & & Rear & 1967 & 2102 \\
\hline & & Middle & 1473 & 2188 \\
\hline & & Front & 3478 & 4260 \\
\hline & & Thumb & 766 & 824 \\
\hline & & \multirow{2}{*}{\multicolumn{3}{|c|}{$\begin{array}{l}\text { Subject No.: } 5 \\
\text { Total load of the foot (gram) }\end{array}$}} \\
\hline & & & & \\
\hline & & Area & Left & Right \\
\hline & & Rear & 1797 & 2233 \\
\hline & & Middle & 1104 & 2217 \\
\hline & & Front & 2851 & 4158 \\
\hline & & Thumb & 424 & 641 \\
\hline
\end{tabular}

When a person stands, the biggest burden occurs in soles of back and front foot for all types of foot, either left or right foot soles [1]. This corresponds to the measurement results using the MAFP tool, which is displayed in red. For a foot with a high arch, the area of the sole of the middle of the foot is small. This corresponds to the measurement result of MAFP. The middle area is displayed in light blue and dark blue. Instead, for a flat foot, the load on the soles of the middle foot is large. The sensors in the medial mid foot, i.e., in sensors 5 and 7, are seen to be exposed to the load. This corresponds to the measurement result of MAFP. The middle area is shown in yellow and green. For a normal type of foot arch it is somewhat difficult to see the comparison with the measurement results using the MAFP 
tool, because it is similar to the type of high arch foot. However, from the measurement results, using the prototype of this designed measuring instrument looks load in the central area is large enough on subjects' numbers 2 and 6 compared to subjects' number 1 and 8 for the high arch type of foot.

\section{Conclusions}

This designed static load gauge can be used to measure the load in any area of the foot (rear, center, front without radius of the soles of the feet, and thumb) for subjects with a shoe size of 40-42. This tool is able to depict the greatest burden on the soles of the back and front feet, either left or right foot soles. As the basis, the tool estimates the type of foot (high arch, normal arch, or flat foot). The proposed measurement tool is designed for affordable price and is to be held in orthopedics hospitals and biometric research centers.

Author Contributions: Conceptualization, D.B.W. and A.S.; methodology, D.B.W.; software, S.K.; validation, D.B.W., A.S. and W.C.; formal analysis, D.B.W. and W.C.; investigation, D.B.W.; resources, A.S.; data curation, S.K.; writing —original draft preparation, D.B.W.; writing—review and editing, W.C., A.G., M.I.; visualization, S.K.; supervision, W.C.; project administration, A.S.; funding acquisition, W.C. All authors have read and agreed to the published version of the manuscript.

Funding: This research received no external funding.

Conflicts of Interest: The authors declare no conflict of interest.

\section{References}

1. Chia, J.K.; Suresh, S.; Kuah, A.; Ong, J.L.; Phua, J.M.; Seah, A.L. Comparative trial of the foot pressure patterns between corrective orthotics, formthotics, bone spur and flat insoles in patients with chronic plantar fasciitis. Ann. Acad. Med. Singap. 2009, 38, 869-875. [PubMed]

2. Periyasamy, R.; Mishra, A.; Anand, S.; Ammini, A.C. Preliminary investigation of foot pressure distribution variation in men and women adults while standing. Foot 2011, 21, 142-148. [CrossRef] [PubMed]

3. Tahmasebi, R.; Karim, M.T.; Satvati, B.; Fatoye, F. Evaluation of standing stability in individuals with flatfeet. Foot Ankle Spec. 2015, 8, 168-174. [CrossRef] [PubMed]

4. Imizumi, K.; Iwakami, Y.; Yamashita, K.; Hiejima, Y. Development of an evaluation system for foot arch types in the elderly using foot pressure distribution data. Eng. Med. Biol. Soc. (EMBC) 2012. [CrossRef]

5. Cavanagh, P.R.; Rodgers, M. The Arch index: A useful measure from footprints. J. Biomech. 1987, 20, 547-551. [CrossRef]

6. Fawzy, O.A.; Arafa, A.I.; Wakeel, M.A.E.; Kareem, S.H.A. Plantar Pressure as a Risk Assessment Tool for Diabetic Foot Ulceration in Egyptian Patients with Diabetes. Clini. Cal. Med. Insights Endocrinol. Diabetes 2014, 7, CMED-S17088. [CrossRef] [PubMed]

7. Kul-Panza, E.; Berker, N. Pedobarographic Findings in Patients with Knee Osteoarthritis. Am. J. Phys. Med. Rehabil. 2006, 85, 228-233. [CrossRef]

8. Wibowo, D.B.; Widodo, A.; Haryadi, G.D.; Caesarendra, W.; Harahap, R. Effect of in-shoe foot orthosis contours on heel pain due to calcaneal spurs. Appl. Sci. 2019, 9, 495. [CrossRef]

9. Cross, R. Standing, walking, running, and jumping on a force plate. Am. J. Phys. 1999, 67, 304-309. [CrossRef]

10. Malvade, P.S.; Joshi, A.K.; Madhe, S.P. IoT Based Monitoring of Foot Pressure Using FSR Sensor. In Proceedings of the International Conference on Communication and Signal Processing, Tamilnadu, India, 6-8 April 2017.

11. Go-Tec Foot Pressure. Available online: https://www.sensorprod.com/pdf/go-tec-foot-plate.pdf (accessed on 31 January 2020).

12. Interlink Electronics, FSR Force Sensing Resistor-Integration Guide and Evaluation Parts Catalog, 400 Series Evaluation Parts with Suggested Electrical Interfaces. Available online: https://www.sparkfun.com/ datasheets/Sensors/Pressure/fsrguide.pdf (accessed on 3 August 2020).

13. Flórez, J.A.; Velásquez, A. Calibration of force sensing resistors (fsr) for static and dynamic applications. IEEE Andescon 2010. [CrossRef]

14. Yung-Hui, L.; Wei-Hsien, H. Effect of shoe inserts and heel height on foot pressure, impact force, and perceived comfort during walking. Appl. Ergon. 2005, 36, 355-362. [CrossRef] [PubMed] 
15. Rodrigo, A.S.; Goonetilleke, R.S.; Xiong, S. Load distribution to minimize pressure-related pain on foot: A model. Ergonomics 2014, 56, 1180-1193. [CrossRef] [PubMed]

16. Druga, C.; Serban, I. Study of foot pressure-sole pressure sensor. In Proceedings of the 7th International Conference on Computational Mechanics and Virtual Engineering (COMEC) 2017, Brasov, Rumania, 16-17 November 2017.

17. Wibowo, D.B.; Suprihanto, A.; Haryanto, I. Body Mass Index Measurement Tool with Software to Evaluate Ideal Body Weight. Patent No. IDS000002589, 4 October 2019.

18. Haryadi, G.D.; Wibowo, D.B.; Ariyanto, M.; Suprihanto, A. Digital Scanning Method for Evaluation of Dimensional Parameters and Identification of Foot Type. Patent No. IDS000002253, 2 April 2019.

19. Wafai, L.; Zayegh, A.; Woulfe, J.; Aziz, S.M.; Begg, R. Identification of Foot Pathologies Based on Plantar Pressure Asymmetry. Sensors 2015, 15, 392. [CrossRef] [PubMed]

20. Fort-Vanmeerhaeghe, A.; Gual, G.; Romero-Rodriguez, D.; Unnitha, V. Lower Limb Neuromuscular Asymmetry in Volleyball and Basketball Players. J. Hum. Kinet. 2016, 50, 135-143. [CrossRef] [PubMed]

21. Wibowo, D.B.; Suprihanto, A.; Haryadi, G.D. Development of Prototype Scanners for Diagnosis of Foot Anomalies. In Higher Education Applied Research Report (PTUPT); DRPM DIKTI: Jakarta, Indonesia, 2018.

(C) 2020 by the authors. Licensee MDPI, Basel, Switzerland. This article is an open access article distributed under the terms and conditions of the Creative Commons Attribution (CC BY) license (http://creativecommons.org/licenses/by/4.0/). 